\title{
BMJ Open Burden of tobacco in Nepal: a systematic analysis from the Global Burden of Disease Study 1990-2017
}

\author{
Gambhir Shrestha (D) , ${ }^{1}$ Prabin Phuyal, ${ }^{2}$ Rabin Gautam, ${ }^{3}$ Rashmi Mulmi, ${ }^{4}$ \\ Pranil Man Singh Pradhan (D) ${ }^{1}$
}

To cite: Shrestha G, Phuyal P, Gautam R, et al. Burden of tobacco in Nepal: a systematic analysis from the Global Burden of Disease Study 1990-2017. BMJ Open 2021;11:e047847. doi:10.1136/ bmjopen-2020-047847

- Prepublication history and additional supplemental material for this paper are available online. To view these files, please visit the journal online (http://dx.doi.org/10.1136/ bmjopen-2020-047847)

Received 13 December 2020 Accepted 05 August 2021

\section{Check for updates}

(c) Author(s) (or their employer(s)) 2021. Re-use permitted under CC BY-NC. No commercial re-use. See rights and permissions. Published by BMJ.

${ }^{1}$ Department of Community Medicine, Maharajgunj Medical Campus, Institute of Medicine, Tribhuvan University, Maharajgunj, Kathmandu, Nepal ${ }^{2}$ B.P. Koirala Institute of Health Sciences, Dharan, Sunsari, Nepal

${ }^{3}$ World Health Organization Country Office for Nepal, Kathmandu, Nepal

${ }^{4}$ Department of Cancer Prevention, Control and Research, B.P. Koirala Memorial Cancer Hospital, Bharatpur, Chitwan, Nepal

Correspondence to Dr Gambhir Shrestha; gamvir.stha@gmail.com

\section{ABSTRACT}

Objective This study systematically reviews the data extracted from the Global Burden of Disease Study and sets out to assess the age-specific and sex-specific mortality and disability attributable to different forms of tobacco from 1990 to 2017, for Nepal.

Design This cross-sectional study extracted data from the Institute for Health Metrics and Evaluation's Global Burden of Disease database, then was quantitatively analysed to show the trends and patterns of prevalence of tobacco use, deaths and disability-adjusted life-years (DALYs) attributable to tobacco use from different diseases from the year 1990 to 2017 in Nepal.

Setting Nepal.

Results In between 1990 and 2015, the age-standardised prevalence of daily tobacco smoking decreased by $33 \%$ in males, $48 \%$ in females and $28 \%$ in both. By 2017 , the age-standardised mortality rate and DALYs attributable to tobacco use, including any form, decreased by $34 \%$ and $41 \%$, respectively, with tobacco smoking having the most contribution. However, the absolute number of deaths and DALYs increased by $39 \%$ and $3 \%$, respectively. An increasing rate of deaths and DALYs attributable to tobacco was noted with an increase in age. Non-communicable diseases were responsible for most deaths and disabilities attributable to tobacco use.

Conclusion The prevalence of smoking along with the age-standardised mortality rate and DALYs shows a decreasing trend. However, attention should be made to implement a strong plan to control all forms of tobacco including secondhand exposure.

\section{INTRODUCTION}

To date, tobacco remains a major public health issue worldwide because of its associated high morbidity and mortality rate. Any forms of tobacco use are harmful to health and kill millions of people every year. ${ }^{1}$ The use of tobacco products in any form either smoking or smokeless or exposure to secondhand smoke has been implicated in many health issues like cardiovascular diseases, respiratory diseases, cancers, non-communicable diseases (NCD) and many more. ${ }^{2}{ }^{3}$ There is no safety margin for exposure to secondhand

\section{STRENGTHS AND LIMITATIONS OF THIS STUDY}

$\Rightarrow$ This study is one of the first studies in Nepal to extracts Global Burden of Disease Study data to present nationally representative data on mortality and disability attributable to tobacco by age, sex and disease.

$\Rightarrow$ This study informs the policy-makers on further strategies to control tobacco use including secondhand smoking.

$\Rightarrow$ This study analyses the secondary data of the Global Burden of Disease Study and hence it has all the limitations pertaining to the data.

$\Rightarrow$ The prevalence of smoking could have been underestimated as the Global Burden of Disease data only takes into account the prevalence of daily smoking and lacked the data for the prevalence of smokeless tobacco and secondhand exposure.

smoke or tobacco smoking and secondhand smoke exposure is equally harmful to health.

According to World Health Organization (WHO), about 1.3 billion people in the world used tobacco products among which more than one billion people were smokers. ${ }^{4}$ Almost $80 \%$ of smokers reside in low-income and middle-income countries. The last two decades have seen a decreasing trend towards the consumption of tobacco in all age groups. In 2000, almost one-third of the world's population $(33.3 \%)$ aged 15 and more used some form of tobacco products, $50 \%$ in males and $16.7 \%$ in females. While, in 2015 , the prevalence of tobacco use dropped to nearly a quarter of the world's population $(24.9 \%)$, $40.3 \%$ in males and $9.5 \%$ in females. ${ }^{1}$ Despite the decreasing prevalence of tobacco use globally, the absolute number of male smokers is growing continuously in SouthEast Asian, African and Eastern Mediterranean regions. The South-East Asian region has the highest prevalence of tobacco use (31\% in 2015) compared with other regions, $49.4 \%$ in males and $12.9 \%$ in females. ${ }^{1}$ According to recent findings from STEPwise 
approach to surveillance (STEPS) survey 2019 in Nepal, around $29 \%$ of adults ( $48 \%$ male and $12 \%$ female) within the age group 15-69 years used any form of tobacco. ${ }^{5}$ In recent times, people have shown a growing preference for smokeless tobacco over smoking in South-East Asia including Nepal. ${ }^{6-8}$ In Nepal, the use of smokeless tobacco is much more common than tobacco smoking and is more prevalent among males (33\%) compared with females $(5 \%) .^{5}$

Despite decreasing prevalence, the number of deaths due to tobacco use continues to rise. Tobacco kills more than 8 million people every year. Among them, about 7 million people die from direct tobacco use while the deaths of about 1.2 million people result from secondhand smoke exposure. ${ }^{4}$ In 2015, smoking alone was responsible for $11.5 \%$ and $6 \%$ of global deaths and disabilityadjusted life-years (DALYs), respectively. ${ }^{9}$ Deaths of about 65000 children per year can be attributed to exposure to secondhand smoke. ${ }^{4}$ The recent estimates show around US \$1.4 trillion of total economic loss results globally from tobacco use which is equivalent to $1.8 \%$ of the world's annual Gross Domestic Product (GDP). ${ }^{10}$ About $40 \%$ of this cost occurred in low-income and middle-income countries. In Nepal, around 27000 deaths occur annually from tobacco use, which comprises about $14.9 \%$ of all deaths. ${ }^{11}$

Given such a significant negative impact of tobacco on public health, navigation of the outcomes of tobacco use in a low-income country like Nepal is of the essence. The issue of tobacco usage has received considerable attention. In response, Nepal implemented the WHO Framework Convention on Tobacco Control (WHO FCTC) in $2006^{12}$ and passed Tobacco Control and Regulatory Bill in 2011 by Parliament. ${ }^{5}$ So far, however, there has been little discussion about trends and patterns of tobacco use and its outcomes in Nepal. Such approaches have an unsatisfactory description of the burden of tobacco in the Nepalese population. This study systematically reviews the data extracted from the Global Burden of Disease (GBD) Study 2017 and sets out to assess the trends in prevalence, mortality and disability attributable to different forms of tobacco in Nepal from 1990 to 2017. Therefore, the findings of this study will make a major contribution informing the policy-makers and public health professionals by providing important insights into evidence for an effective tobacco control programme in Nepal.

\section{METHODS}

\section{Data sources and study settings}

The GBD study 2017 was a comprehensive epidemiological study that reported the trends and patterns in morbidity and mortality in 195 countries from major injuries, diseases and risk factors to health at the global, regional and national level. The study design, metrics and analysis are published elsewhere. ${ }^{13}$ The Institute for Health Metrics and Evaluation (IHME) coordinated the GBD study 2017 and used the data from several published and unpublished literature, survey and surveillance data, hospital and clinics data to estimates the deaths and disability attributable to 84 risk factors for 195 countries by age and sex. ${ }^{1314}$

The Nepal GBD 2017 study used data from over 90000 sources covering the years between 1990 and 2017. These data sources included in Nepal's burden of disease estimates mainly data from the 1971 to 2011 Nepal Population and Housing Census, disease registries such as the Kidney Disease Data Centre maintained by the International Society of Nephropathy, epidemiological surveillance such as the WHO Disease Observatory, periodic and ad hoc large household surveys such as Nepal Demographic Health Surveys, Multiple Indicator Cluster Surveys and Nepal STEPS Non-Communicable Risk Factor Surveys, Nepal Global Youth Tobacco Survey, Nepal Behavioural Surveillance Survey, Nepal Hospital Inpatient Discharges Record, Health Management Information System, published scientific literature, reports and administrative records. ${ }^{15}$

The GBD database was used for the extraction of data related to mortality and DALYs of all causes and other major public health issues of Nepal like cardiovascular diseases, NCDs, diabetes and kidney disease, all neoplasms including benign and malignant, and tuberculosis from the year 1990 to $2017 .^{16}$

\section{Patient and public involvement statement}

This study used the data freely available from the IHME's GBD database. Patients were not involved in the design, recruitment or conduct of the study. Results of this study will be made publicly available through publication.

\section{Definition of terminology}

Years of life lost (YLLs) are calculated by multiplying the number of deaths at each age by a standard life expectancy at that age. Years lived with disability (YLDs) is the number of years of life lived with health loss weighted by the severity of the disabling sequelae of diseases and injuries. DALY is the key summary measure of population health used in GBD to quantify health loss which allows comparison of health loss across different diseases and injuries. They are a measure of the number of years of healthy life that are lost due to death, nonfatal illness or impairment, and thus, they are calculated as the sum of YLLs and YLDs. ${ }^{1417}$

Uncertainty interval (UI) is a range of values that is likely to include the correct estimate of disease burden for a given cause. Narrow UIs indicate that evidence is strong, while wide UIs show that evidence is weaker. ${ }^{14} 17$

The term tobacco includes tobacco use in all forms either smoking or smokeless or both.

\section{Statistical analysis}

The extracted data from IHME were imported into Microsoft Excel, then were quantitatively analysed and presented in the graphical, tabular forms and histograms to show the trends and patterns in age-sex-specific 


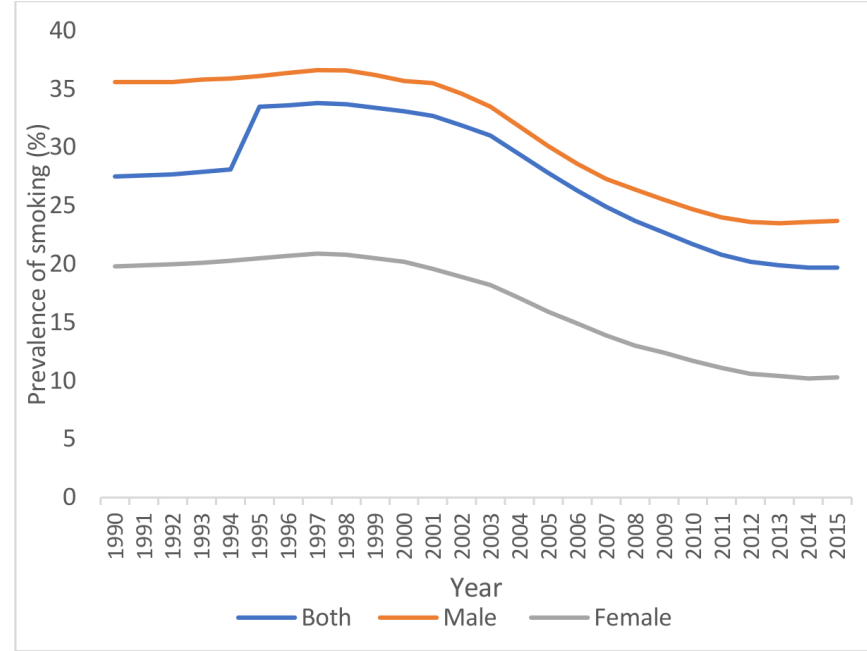

Figure 1 Prevalence of smoking from the year 1990 to 2015 in Nepal.

mortality and DALYs in Nepal. The age-standardised prevalence of tobacco use only in form of daily tobacco smoking was available up to the year 2015. A percentage change was calculated to present the difference in mortality and DALYs between 1990 and 2017. An UI of $95 \%$ was presented to show the strength of the estimates.

\section{RESULTS}

Here, we report the GBD study results for Nepal on the prevalence of tobacco use, mortality and burden caused by different forms of tobacco, smoking and smokeless tobacco, between 1990 and 2017.

\section{Tobacco smoking}

The trend of daily tobacco smoking is in decreasing trend during the period 1990-2015 in both sexes. In 1990, the age-standardised prevalence of tobacco smoking at all ages was $27.5 \%$ for both sexes. The prevalence was more for males $(35.6 \%)$ than the females $(19.8 \%)$. In 2015 , the prevalence of tobacco smoking decreased to $19.7 \%$ in both sexes at all ages, with male $23.7 \%$ and female $10.3 \%$ (figure 1).

\section{Deaths and DALYs}

In Nepal, both the age-standardised mortality rate and the DALYs attributable to tobacco are in decreasing trend from 1990 to 2017 (figure 2). The age-standardised attributable deaths to tobacco use, including all forms, decreased $(34.5 \%)$ in the general population from 216 (95\% UI 183-258) per 100000 in 1990 to 141 (95\% UI $120-163)$ per 100000 in 2017. While DALYs decreased by 41.3\% from 5474 per 100000 in 1990 to 3216 per 100000 in 2017. This finding was found in both males and females. Similarly, over the same time, the age-standardised deaths and DALYs attributable to tobacco smoking, chewing tobacco, secondhand smoking, showed a falling trend for both sexes and males and females separately (table 1 ). In absolute terms, the attributable deaths at all ages to

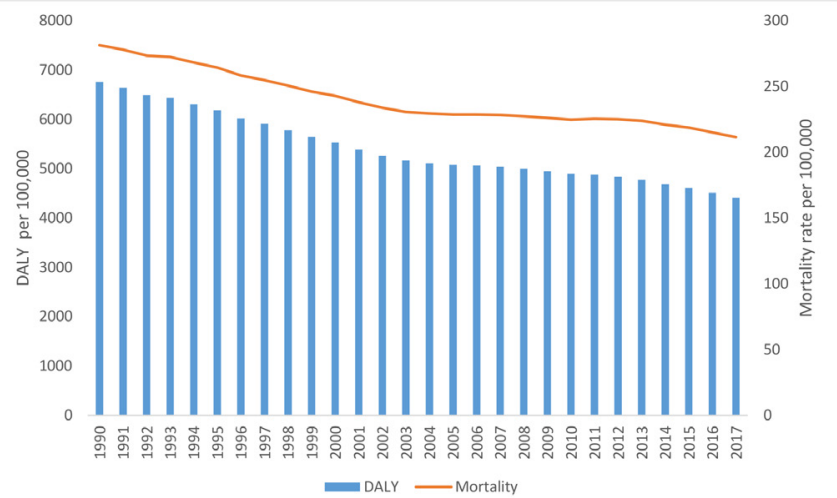

Figure 2 Trend of age-standardised mortality rate and DALYs attributable to tobacco from 1990 to 2017 in Nepal. DALYs, disability-adjusted life-years.

tobacco use, including all forms, increased $(38.99 \%)$ in the general population (both male and female) from 19372 (95\% UI 16060-23310) in 1990 to 26926 (95\% UI 22826-31135) in 2017. While DALYs for all ages due to tobacco use increased $(10.52 \%)$ in males from 403665 (95\% UI $319794-512870)$ in 1990 to 446132 (95\% UI $364622-524648)$ in 2017 , it decreased $(8.78 \%)$ in females from 280977 (95\% UI $205487-373384$ ) in 1990 to 256301 (95\% UI 205569-316573) in 2017 (online supplemental table 1 ).

Figure 3 demonstrates a clear trend of the increasing rate of deaths and DALYs attributable to tobacco with an increase in age. Around 27000 deaths are attributable to tobacco comprising $90 \%$ deaths due to NCDs. Similarly, more than 702000 DALYs were attributable to tobacco use comprising $89 \%$ DALYs for NCDs (figure 4).

\section{Cardiovascular diseases}

The age-standardised deaths from cardiovascular diseases showed falling trends in both sexes due to tobacco use (of all types), tobacco smoking and in females due to secondhand smoking, while age-standardised deaths showed increasing trends in males from secondhand smoking. The age-standardised DALYs from cardiovascular diseases showed falling trends in both sexes due to tobacco use, tobacco smoking and secondhand smoking. The major cause of deaths and DALY in cardiovascular disease attributable to tobacco was found to be smoking.

\section{Diabetes and kidney diseases}

The attributable deaths and DALYs from diabetes and kidney diseases showed rising trends in both sexes due to tobacco smoking and secondhand smoking in both sexes.

\section{Neoplasms}

The age-standardised deaths and age-standardised DALYs from all neoplasms showed falling trends in both sexes due to tobacco use, tobacco smoking, chewing tobacco and secondhand smoking. 


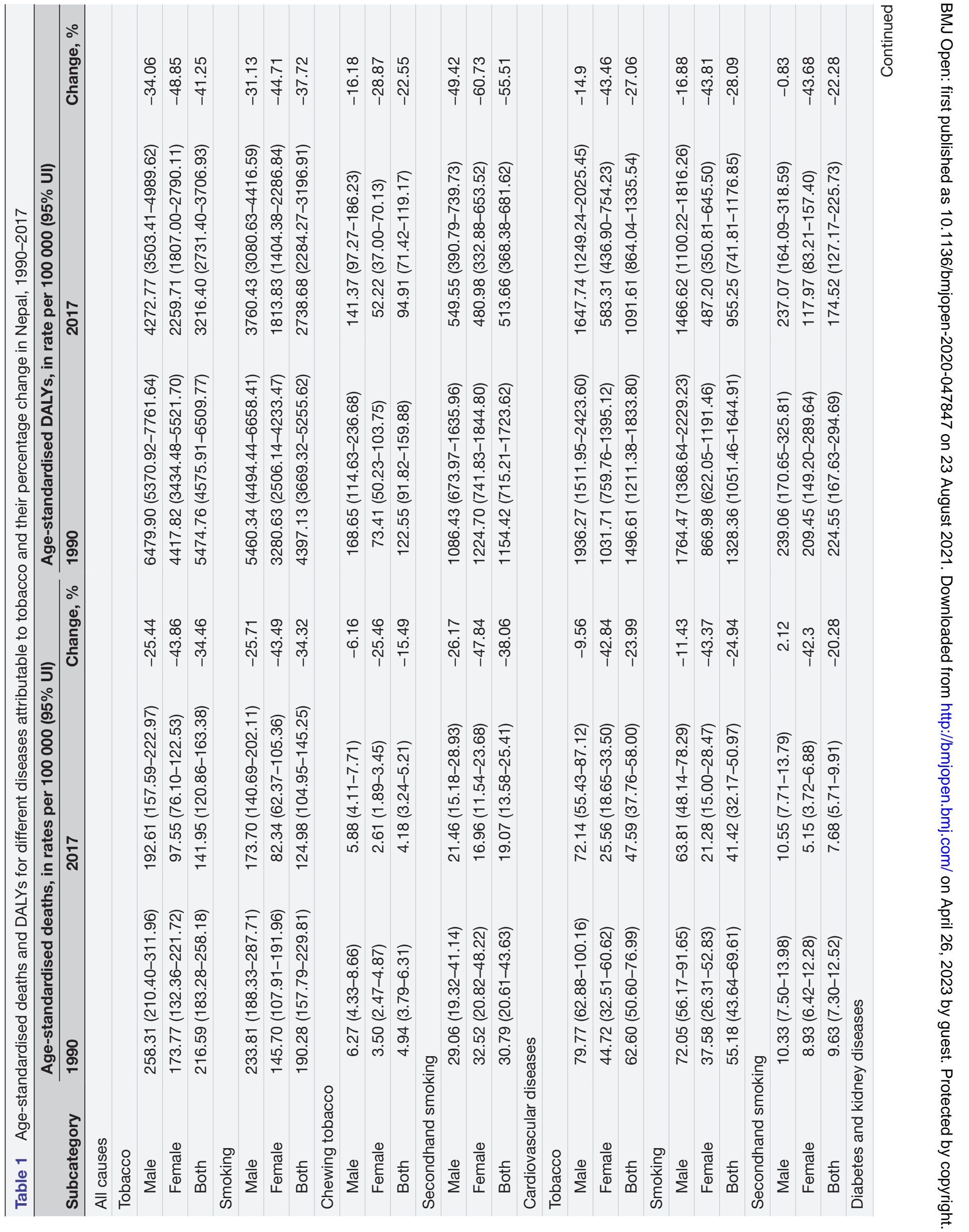


ナ.

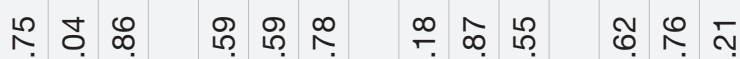

N

গิষ

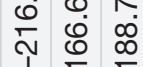

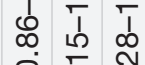

范

เீ. స

மீ)

लें ฐं

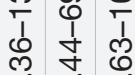

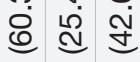

下

बீं ซ்

ธิธ ช

र

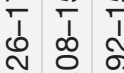

ث

ชิ

ิํำ

สิ ส ส

ᄃ

ธ) ชิ ๙ิ

过

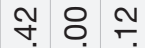

வ

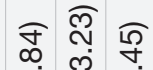

œ

仓े

๓

क

チ

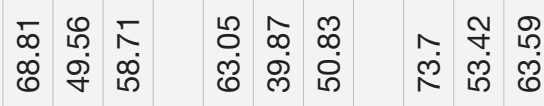

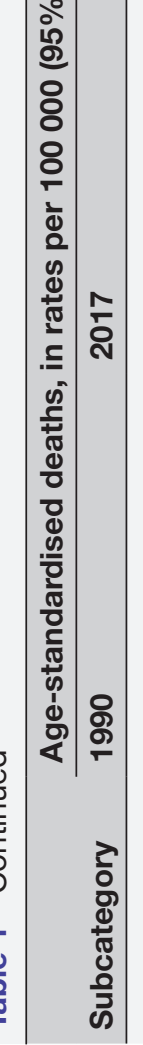

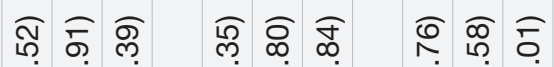

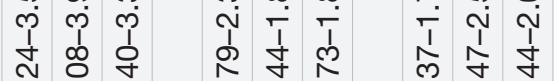

ᄃ $匚$

อ อ อ

อ อ 잉

워 ผ

กิ

กิ

ง $ง$ ก

일

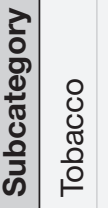

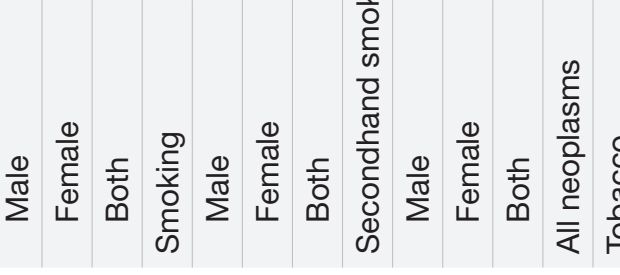

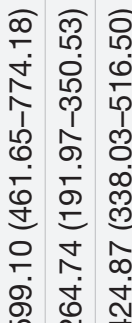

กิ กิ จุ

กู

$\begin{array}{llll}1 & 1 & 1 \\ \infty & 0 & \text { g }\end{array}$

లై

人

กั ำ

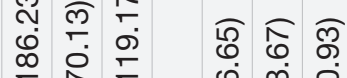

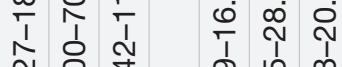

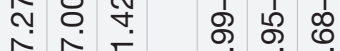

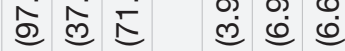

กิ సิ ธా

尽

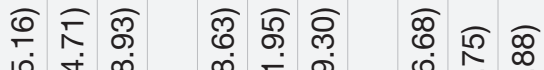

岗

$\begin{array}{llllll}1 & 1 & 1 & 1 & 1 & 1 \\ 0 & 0 & 1 & 1 & 1 & 1\end{array}$

ले $\overline{1}$

ธำ

व ले $\infty$

Е

๑

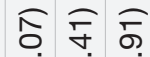

กิ में लं

मे

过

ปे

๓

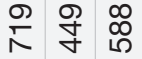

㲾

\&

웅 요

ก ช

i

సু হ

苑

œ

ลูป

శ.

क्र

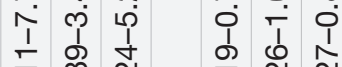

ت্்

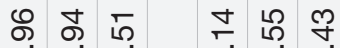

ஸे ㅇำ

$\infty-\infty$

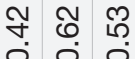

ம்

б్ర

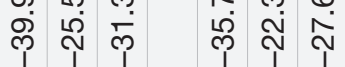

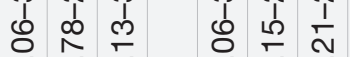

छิ

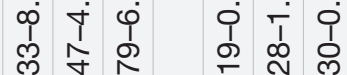

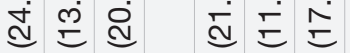

过

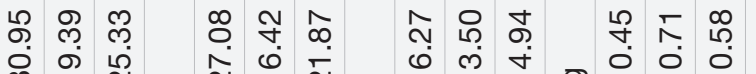

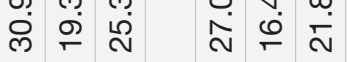

○ 0000

0
0
0
$\mathbb{8}$
0
$\frac{0}{0}$

$\frac{0}{\frac{0}{0}}$

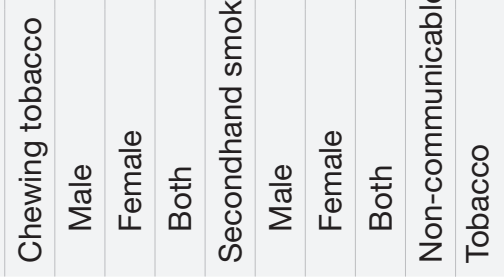




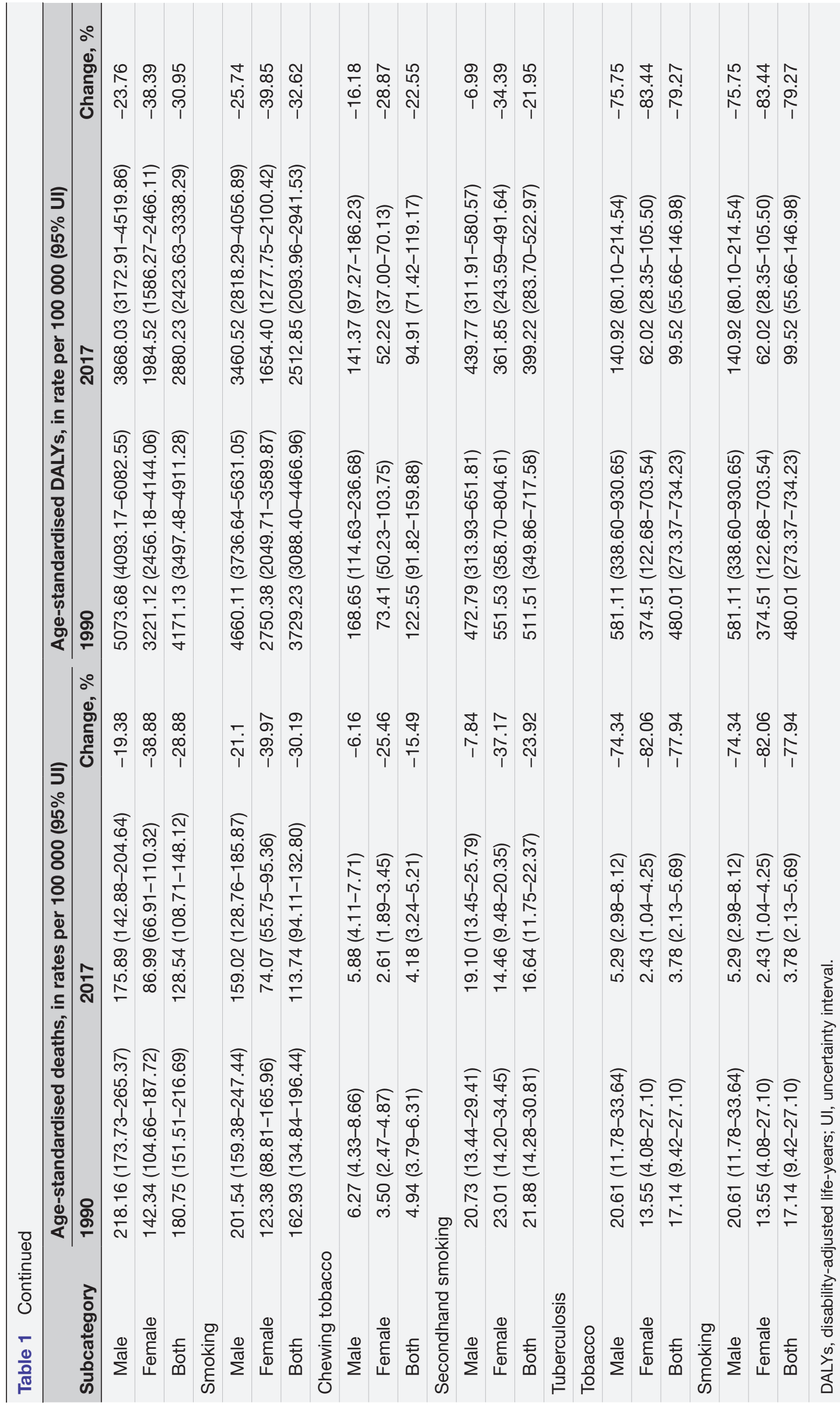




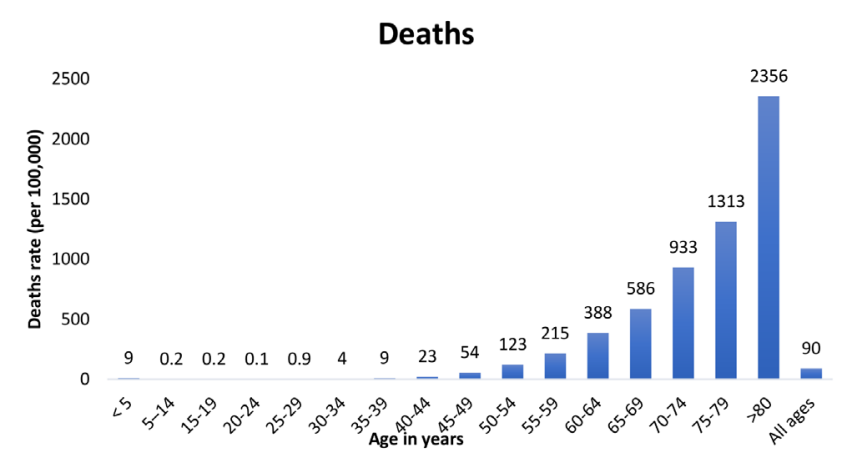

A

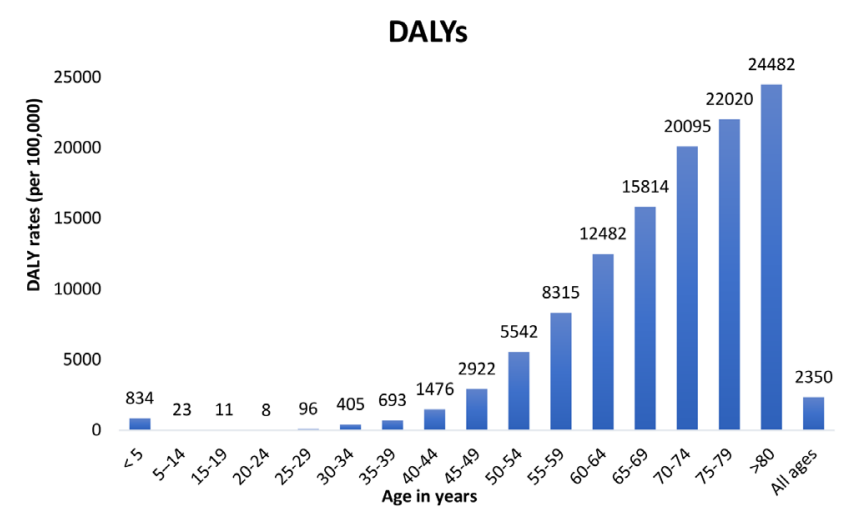

B

Figure 3 Agewise deaths $(A)$ and DALYs $(B)$ rates in all causes in both sexes attributable to tobacco, including all types, in 2017. DALYs, disability-adjusted life-years.

\section{Non-communicable diseases}

The attributable age-standardised death from NCD due to tobacco use decreased (29\%) from 180 (95\% UI 115-216) in 1990 to 128 (95\% UI 108-148) in 2017 in both sexes, with deaths occurring mostly from tobacco smoking. The DALYs also decreased by $31 \%$ from 4171 (95\% UI $3197-$ 4911) in 1990 to 2880 (95\% UI 2423-3338) in 2017 in both sexes, with disability mostly resulting from smoking. Over the same period, deaths and DALYs from NCDs showed decreasing trends in both sexes due to tobacco smoking, secondhand smoking and chewing tobacco,

\section{Tuberculosis}

The attributable age-standardised deaths and DALYs from tuberculosis due to tobacco use showed falling trends in both sexes.

\section{DISCUSSION}

\section{Prevalence and patterns of tobacco use}

The GBD study results indicate that throughout the time between 1990 and 2015, the prevalence of daily tobacco smoking decreased by $33 \%$ in male $(35.6 \%$ in 1990 and $23.7 \%$ in 2015 ), by $48 \%$ in female (19.8\% in 1990 and

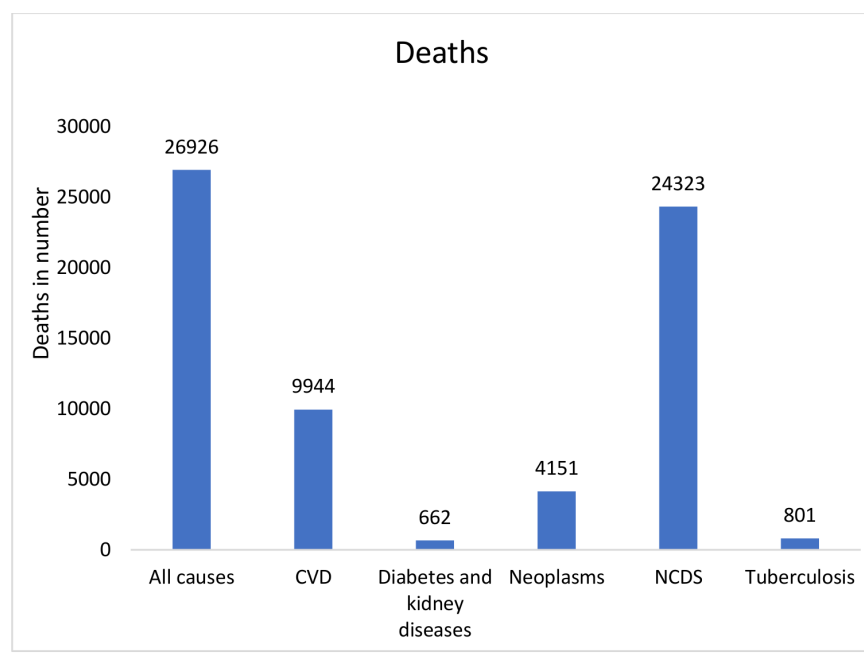

A

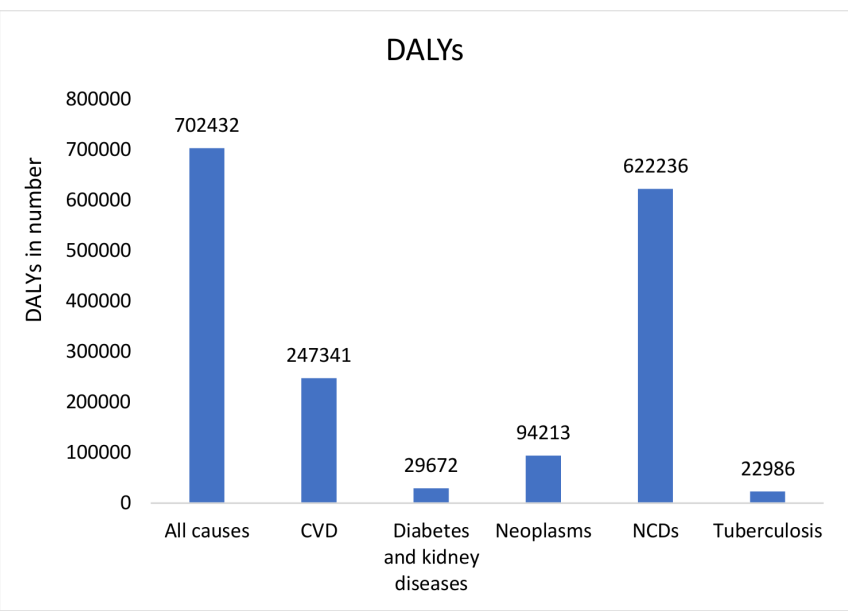

B

Figure 4 All-age deaths (A) and DALYs (B) from different diseases attributable to tobacco use (including all types) in Nepal in 2017. CVD, cardiovascular disease; DALYs, disability-adjusted life-years; NCDs, non-communicable diseases.

$10.3 \%$ in 2015 ) and by $28 \%$ in the general population (27.5\% in 1990 and $19.7 \%$ in 2015). One reason for the decrease in the prevalence of daily tobacco use could be Nepal's implementation of WHO FCTC in $2006^{12}$ and Tobacco Control and Regulatory Bill in 2011, ${ }^{5}$ which regulate the law of tobacco use in Nepal. In reviewing previous literature, it is evident that gender, geographical and socioeconomic variation do play a role in observed differences in the pattern of tobacco use. In Nepal, the use of tobacco products is practised extensively in the elderly population, males, people with lower education levels, rural areas, mountainous areas than in plain areas, and Far-western and Mid-western regions than in Eastern, Central and Western regions. ${ }^{18}$ In addition to that, in Nepal, people in mountainous areas tend to smoke more while, people in plain areas tend to chew tobacco more. ${ }^{18}{ }^{19}$ Elderly people have different beliefs around tobacco use, like continuing tobacco does no 
harm and stopping tobacco does not improve health status. ${ }^{20}$ People who are less educated might have a lower level of awareness of the harmful hazards of tobacco use. However, in recent times, males of the young age group have high tobacco consumption. ${ }^{6}$ A similar pattern of variation in tobacco use was noticed in the Southeast Asian population. The higher prevalence of smoking in males was observed in Asian countries like Malaysia, the Philippines, Singapore, Vietnam, Indonesia, Maldives and Bangladesh. ${ }^{21}{ }^{22}$ In these countries, gender seems to be an important determinant of the initiation of the smoking habit and for perpetuating it. Social norms and the prohibition of tobacco use can be one of the factors responsible for the lower prevalence of tobacco use in the female population in Southeast Asian countries. ${ }^{23}$ Smokeless form of tobacco was common in countries like India, Nepal, Bangladesh, Maldives and Cambodia. ${ }^{22}$ Increasing age, poverty and poor education were associated with higher consumption of tobacco in these countries.

It was evident from the results that, age-standardised rates of death and disability due to smokeless tobacco are in decreasing, however, the absolute number of deaths and disabilities due to smokeless tobacco is increasing. In recent years in the Southeast Asia region, including Nepal, there is a clear increase in preference to using smokeless tobacco over tobacco smoking, with a higher prevalence of smokeless tobacco in males. ${ }^{6-8}{ }^{24}$ Smokeless tobacco is associated with a higher risk of getting cancer ${ }^{25}$ and cardiovascular risk factors like hypertension, metabolic syndrome and cardiovascular events like acute coronary syndrome $^{26}$ than non-tobacco users, although less than tobacco smoking. The increased prevalence of smokeless tobacco in the Nepalese population and the potential increase in the risk of cancer associated with it might be the reason for the increase in disability rate from all neoplasms due to chewing tobacco. According to a study in Nepal, most of the consumers of smokeless tobacco are unaware of its harmful health hazards. ${ }^{27}$ Studies have shown that smokers tend to perceive smokeless tobacco as less harmful than smoking. ${ }^{28}$ This belief might exist among smokers in Nepal and the extent of such beliefs needs to be explored in detail. The production of smokeless tobacco products is unhindered in Nepal and the increased import of smokeless from the neighbouring country, India made the products easily accessible all over the country. ${ }^{27}$ And, owing to the government's lower taxation imposed on smokeless products compared with smoking tobacco products, smokeless tobacco products have an added affordability. ${ }^{6}$ Tobacco products such as bidis and smokeless tobacco are perceived as 'hard to tax' due to their more informal nature. Thus, all these factors with more emphasis on tobacco control policy on tobacco smoking over smokeless tobacco with lack of awareness towards the hazards of smokeless tobacco products seem to be the cause for shifting the preference of consumers from smoking to smokeless tobacco.

The results indicate that the age-standardised rates of death among males due to cardiovascular diseases, and age-standardised deaths and disability due to diabetes and kidney diseases in both sexes, attributable to secondhand smoking are in the increasing pattern. At the global level, around $40 \%$ of children, $33 \%$ of male non-smokers and $35 \%$ of female non-smokers are estimated to have been exposed to secondhand smoke regularly, with Southeast Asia and the Western Pacific region accountable for $50 \%$ of the globe's total burden from secondhand smoke exposure. ${ }^{29}$ Most of the deaths attributable to secondhand smoke occurred from ischaemic heart disease in adults and lower respiratory tract infections in children, women having the greatest burden among all. Most DALYs lost secondary to secondhand smoke exposure occurred due to lower respiratory tract infections and ischaemic heart diseases, children being the most affected ones. ${ }^{29}$ In Nepal, public transports and restaurants are the major areas of secondhand smoke exposure in public places, while homes and workplaces are indoor areas of secondhand smoke exposure. ${ }^{5}$

\section{Deaths and DALYs attributable to tobacco}

Tobacco use was the second most common risk factor for deaths and the third most common risk factor for total DALYs in Nepal in $2017 .{ }^{30}$ In numbers, $14.73 \%$ (95\% UI 12.52-16.58) of total deaths and 7.8\% (95\% UI 6.68-9.06) of total DALYs were attributed to tobacco use in 2017. ${ }^{30}$ In between 1990 and 2017, the total deaths attributable to tobacco use, including any form, in all ages increased by $39 \%$ in the general population (both males and females) and DALYs attributable to tobacco use, including any form, in all ages increased by $11 \%$ males but decreased by $9 \%$ in females, with tobacco smoking having the most contribution. Also, in 2017 most of the tobacco attributable deaths were due to cardiovascular disease, diabetes, neoplasm and kidney disease. Between 1990 and 2017, tobacco attributable disease occupied a larger proportion of cause of death in Nepal. In contrary to an overall decrease in the prevalence of tobacco use and age-standardised deaths and DALYs in both males and females in recent decades, the total deaths and DALYs were higher in 2017 compared with 1990. One plausible explanation for this pattern could the population growth in Nepal, 29 million in 2019 compared with 18.9 million in $1990 .{ }^{31}$ The rising number of tobacco consumers despite the overall decrease in the prevalence of tobacco use can be attributed to population growth compared with 1990. Furthermore, the elderly population tends to have smoked for more decades considering they started consuming tobacco from an early age. Thus, they tend to have the highest exposure to tobacco which can support a fact that the mortality attributable to tobacco becomes evident usually after 2-3 decades of tobacco use. ${ }^{32}$ This evidence also explains the reason why there are increasing deaths and disabilities with an increase in age. Consequently, the deaths attributed to tobacco use may continue to rise in the long run despite the decrease in the prevalence of tobacco use. 


\section{Policy related to tobacco in Nepal}

In response to the global tobacco epidemic, WHO launched a global public health treaty in 2003 named WHO FCTC. ${ }^{33}$ Nepal signed the WHO FCTC in 2003 with the ratification of the treaty in $2006 .{ }^{12}$ In 2008 , to efficiently implement the FCTC, WHO launched the MPOWER policy to lower the tobacco demand in individual countries, ${ }^{34}$ which was adopted by Nepal. The Parliament of Nepal passed the Tobacco Control and Regulatory Bill in 2011 incorporating the provisions of WHO FCTC which is currently the primary law that governs tobacco use. This act regulates the use of tobacco in public workplaces and public transport, advertisement and promotion of any kind of tobacco products, and packaging and labelling of tobacco products. However, the question that arises is how effective the law is, and how effective we have been in protecting people from tobacco use, tobaccorelated deaths and disability. The decreasing trends in the prevalence of tobacco use and age-standardised deaths and DALYs attributable to tobacco suggest that tobacco control has been effective so far. Nepal received a Bloomberg Philanthropies Award for Global Tobacco Control in 2015 for its work in control and reduction of tobacco product use by warning people about the hazards of tobacco use. ${ }^{35}$ The tobacco act has emphasised more on packaging and promotion to abate the consumption of tobacco products. In the STEPS survey conducted in $2019,75.7 \%$ of adults noticed health warnings on tobacco packages and $44.8 \%$ of current users thought of quitting because of such warnings. However, the tobacco act is limited by a lack of knowledge on the implementation of regulations in public places and around the educational hubs. Though the control of tobacco use in Nepal appears well in the last few decades, the progress seems static in recent times. The STEPs survey conducted in Nepal in 2019 showed only a minor drop in the prevalence of former smokers or former smokeless tobacco users in comparison to 2013. ${ }^{5}$ Tobacco control contributes to improving the health of its consumers and is very important for economic development. On average, the average amount of money spent per year on cigarettes is around $11 \%$ of GDP per capita. ${ }^{5}$ Nepal currently imposes a tobacco tax of just $15.5 \%$ of retail price (excluding valueadded tax (VAT)) which is the lowest among the South Asian countries and far below the WHO guideline of $70 \%$ of the retail price. ${ }^{36}$ Tobacco taxation increases the retail price of tobacco products and reduces the demand therefore is considered to be the most cost-effective method in tobacco control. ${ }^{37} \mathrm{~A} 10 \%$ increase in the price of tobacco products is expected to reduce the demand by $5 \%-10 \%$ in lower-income and middle-income countries. ${ }^{4}$ Given the high burden of tobacco use in Nepal, an increment of the tax on tobacco products should be given high priority.

\section{Limitations of study}

There are a few limitations to the study. First is the lack of primary data sources from Nepal and those included sources used in GBD are limited in scope, coverage and quality. Nepal also lacks a cause of death surveillance system to document disease-related deaths. However, in resource-limited countries like Nepal, where reliable health statistics are limited, the GBD data provide nationally representative findings, providing evidence-based strategies for policy-making. Second, the prevalence of smoking could have been underestimated as the GBD data only takes into account the prevalence of daily smoking and lacked the data for the prevalence of smokeless tobacco and secondhand exposure. This could have resulted in an underestimation of attributable disease burden especially in populations who tend to use less tobacco every day. Also, the data did not account for the duration and intensity of tobacco use. Third, the burden estimates are limited by not considering indoor and outdoor air pollution. Nepal has experienced a massive increase in air pollution during the time in most of the cities, which could confound the findings.

\section{CONCLUSIONS}

This study is one of the first studies in Nepal to show the trend of mortality and DALY attributable to tobacco use. There is a decreasing trend in the prevalence of smoking, age-standardised mortality and DALYs between 1990 and 2017. However, there was a more than one-third increase in crude mortality rate. NCDs contributed the most deaths and disabilities attributable to tobacco. There is a huge increase in deaths and DALY due to chewing tobacco from 1990 to 2017. Awareness along with the strong implementation of tobacco control strategies on all forms of tobacco including secondhand exposure and increasing taxation can further help to decrease the trend in the future. There is also a need for a robust and reliable data representative of all regions in Nepal to understand the effect of tobacco control policies.

Twitter Gambhir Shrestha @gamvir_shrestha and Pranil Man Singh Pradhan @ PranilMSPradhan

Acknowledgements We would like to thank The Institute for Health Metrics and Evaluation's Global Burden of Disease for the data for this study.

Contributors GS: conceptualisation, methodology, software, formal analysis, supervision, writing-original draft preparation. PP: software, formal analysis, visualisation, writing-original draft preparation. RG: conceptualisation, methodology, software, formal analysis, writing-original draft preparation. RM: conceptualisation, Visualisation, writing-reviewing, and editing. PMSP: methodology, visualisation, writing-reviewing and editing. All authors revised, read and approved the final version of the manuscript.

Funding The authors have not declared a specific grant for this research from any funding agency in the public, commercial or not-for-profit sectors.

Competing interests None declared.

Patient consent for publication Not required.

Provenance and peer review Not commissioned; externally peer reviewed.

Data availability statement Data are available in a public, open access repository (http://ghdx.healthdata.org/). All data relevant to the study are included in the article or uploaded as online supplemental information. All data relevant to the study are included in the article and can be assessed through the website http://ghdx. healthdata.org/.

Supplemental material This content has been supplied by the author(s). It has not been vetted by BMJ Publishing Group Limited (BMJ) and may not have been 
peer-reviewed. Any opinions or recommendations discussed are solely those of the author(s) and are not endorsed by BMJ. BMJ disclaims all liability and responsibility arising from any reliance placed on the content. Where the content includes any translated material, BMJ does not warrant the accuracy and reliability of the translations (including but not limited to local regulations, clinical guidelines, terminology, drug names and drug dosages), and is not responsible for any error and/or omissions arising from translation and adaptation or otherwise.

Open access This is an open access article distributed in accordance with the Creative Commons Attribution Non Commercial (CC BY-NC 4.0) license, which permits others to distribute, remix, adapt, build upon this work non-commercially, and license their derivative works on different terms, provided the original work is properly cited, appropriate credit is given, any changes made indicated, and the use is non-commercial. See: http://creativecommons.org/licenses/by-nc/4.0/.

\section{ORCID iDs}

Gambhir Shrestha http://orcid.org/0000-0002-9975-9804

Pranil Man Singh Pradhan http://orcid.org/0000-0002-0066-8583

\section{REFERENCES}

1 World Health Organization. WHO global report on trends in prevalence of tobacco use 2000-2025. 3rd Edn, 2019. https:// www.who.int/publications/i/item/who-global-report-on-trends-inprevalence-of-tobacco-use-2000-2025-third-edition

2 U.S. Department of Health and Human Services. The health consequences of smoking: a report of the surgeon General. Atlanta: Centers for Disease Control and Prevention, 2004. https://pubmed. ncbi.nlm.nih.gov/20669512

3 Centers for Disease Control and Prevention (US), U.S. Department of Health and Human Services. The health consequences of involuntary exposure to tobacco smoke: a report of the surgeon General, 2006. https://www.ncbi.nlm.nih.gov/books/NBK44324/

4 World Health Organization. Tobacco, 2020. Available: https://www. who.int/news-room/fact-sheets/detail/tobacco [Accessed 2 Aug 2020].

5 Nepal Health Research Council. Noncommunicable Disease Risk Factors : STEPS Survey Nepal 2019, 2019. http://nhrc.gov.np/wpcontent/uploads/2020/04/NEPAL\%E2\%80\%93Noncommunicabledisease-risk-factors-STEPS-Survey-2019-\%E2\%80\%93-TobaccoFactsheet.pdf

6 Shrestha N, Mehata S, Pradhan PMS, et al. A nationally representative study on socio-demographic and geographic correlates, and trends in tobacco use in Nepal. Sci Rep 2019;9:1-11.

7 Suliankatchi RA, Sinha DN, Rath R, et al. Smokeless tobacco use is "replacing" the smoking epidemic in the South-East Asia Region. Nicotine Tob Res 2019;21:95-100.

8 Dobe M, Sinha DN, Rahman K. Smokeless tobacco use and its implications in WHO South East Asia region. Indian J Public Health 2006;50:70-5.

9 GBD 2015 Tobacco Collaborators. Smoking prevalence and attributable disease burden in 195 countries and territories, 19902015: a systematic analysis from the global burden of disease study 2015. Lancet 2017;389:1885-906.

10 Goodchild M, Nargis N, Tursan d'Espaignet E. Global economic cost of smoking-attributable diseases. Tob Control 2018;27:58-64.

11 World Health Organization. Factsheet 2018 Nepal, 2018. Available: https://apps.who.int/iris/bitstream/handle/10665/272687/wntd 2018_nepal_fs.pdf?sequence=1 [Accessed 3 Aug 2020].

12 Ministry of Health and Population, Government of Nepal. Brief profile on tobacco control in Nepal. Ministry of Health and Population Nepal, 2012. https://www.who.int/fctc/reporting/party_reports/nepal_ 2012_annex2_tobacco_profile.pdf

13 Institute for Health Metrics and Evaluation. Global burden of disease study 2017 (GBD 2017) data resources | GHDx. GBD online database, 2019. Available: http://ghdx.healthdata.org/gbd-2017

14 GBD 2017 Disease and Injury Incidence and Prevalence Collaborators. Global, regional, and national incidence, prevalence, and years lived with disability for 354 diseases and injuries for 195 countries and territories, 1990-2017: a systematic analysis for the global burden of disease study 2017. Lancet 2018;392:1789-858.
15 Nepal Health Research Council, Ministry of Health and Population, Monitoring Evaluation and Operational Research. Nepal burden of disease 2017: a country report based on the global burden of disease 2017 study. Kathmandu, Nepal, 2019. http://nhrc.gov.np/wp-content/ uploads/2019/04/NBoD-2017_NHRC-MoHP.pdf

16 Institute for Health Metrics and Evaluation. GBD results tool | GHDx. Institute for health metrics and evaluation, 2019. Available: http:// ghdx.healthdata.org/gbd-results-tool

17 Murray CJL, Lopez AD. Measuring the global burden of disease. $N$ Engl J Med 2013;369:448-57.

18 Sreeramareddy CT, Ramakrishnareddy N, Harsha Kumar HN, et al. Prevalence, distribution and correlates of tobacco smoking and chewing in Nepal: a secondary data analysis of Nepal Demographic and Health Survey-2006. Subst Abuse Treat Prev Policy 2011;6:1-9.

19 Khanal V, Adhikari M, Karki S. Social determinants of tobacco consumption among Nepalese men: findings from Nepal Demographic and Health Survey 2011. Harm Reduct J 2013;10:40

20 Fisher EB, Hill RD. Perspectives on older smokers. Chest 1990;97:517-8.

21 Morrow M, Barraclough S. Tobacco control and gender in Southeast Asia. Part I: Malaysia and the Philippines. Health Promot Int 2003;18:255-64.

22 Sreeramareddy CT, Pradhan PMS, Mir IA, et al. Smoking and smokeless tobacco use in nine South and Southeast Asian countries: prevalence estimates and social determinants from Demographic and Health Surveys. Popul Health Metr 2014;12:22

23 Rani M, Thamarangsi T, Agarwal N. Youth tobacco use in south-east Asia: implications for tobacco epidemic and options for its control in the region. Indian J Public Health 2017;61:12.

24 Sinha DN, Gupta PC, Ray C, et al. Prevalence of smokeless tobacco use among adults in WHO South-East Asia. Indian J Cancer 2012;49:342.

25 Boffetta P, Hecht S, Gray N, et al. Smokeless tobacco and cancer. Lancet Oncol 2008:9:667-75.

26 Gupta R, Gupta N, Khedar RS. Smokeless tobacco and cardiovascular disease in low and middle income countries. Indian Heart J 2013;65:369-77.

27 Sinha DN, Bajracharya B, Khadka BB, et al. Smokeless tobacco use in Nepal. Indian J Cancer 2012;49:352-6.

28 O'Connor RJ, McNeill A, Borland R, et al. Smokers' beliefs about the relative safety of other tobacco products: findings from the ITC collaboration. Nicotine Tob Res 2007;9:1033-42.

29 Öberg M, Jaakkola MS, Woodward A, et al. Worldwide burden of disease from exposure to second-hand smoke: a retrospective analysis of data from 192 countries. Lancet 2011;377:139-46.

30 Institute for Health Metrics and Evaluation. GBD compare | IHME viz hub. global burden of disease, 2015. Available: https://vizhub. healthdata.org/gbd-compare/

31 World Bank. Data: population, total-Nepal, 2020. Available: https:// data.worldbank.org/indicator/SP.POP.TOTL?locations=NP [Accessed 2 Aug 2020].

32 Lopez AD, Collishaw NE, Piha T. A descriptive model of the cigarette epidemic in developed countries. Tob Control 1994;3:242-7.

33 World Health Organization. WHO framework convention on tobacco control; 2003. http://apps.who.int/iris/bitstream/handle/10665/42811/ 9241591013.pdf?sequence $=1$ [Accessed 15 Aug 2020].

34 World Health Organization. WHO report on the global tobacco epidemic, 2008: the MPOWER package. Geneva, Switzerland: World Health Organization, 2008. https://apps.who.int/iris/handle/10665/ 43818

35 Bloomberg Philanthropies. 2015 Bloomberg Philanthropies awards for global tobacco control: meet the winning organizations, 2015. http://www.bloomberg.org/blog/2015-bloomberg-philanthropiesawards-global-tobacco-control-meet-winning-organizations/

36 World Health Organization. WHO report on the global tobacco epidemic 2019: offer help to quit tobacco use. 2019. Geneva, Switzerland: World Health Organization, 2020. https://www.who.int/ teams/health-promotion/tobacco-control/who-report-on-the-globaltobacco-epidemic-2019

37 World Health Organization. WHO technical manual on tobacco Tax administration, 2010. Available: https://www.who.int/tobacco/ publications/tax_administration/en/ 